\title{
Formação de Palauras com Adjetivos de Origem Tupi no Português Amazônico
}

\author{
Orlando da Silva AZEVEDO* \\ Felício Wessling MARGOTTI** \\ Ilna Kelly Ferreira dos SANTOS
}

* Doutor (2013) em Linguística pela Universidade Federal de Santa Catarina - Campus de Florianópolis (UFSC). Docente da Universidade Federal do Amazonas (UFAM) - Campus de Manaus. Contato: orsasilva@gmail.com.

** Doutor (2004) em Letras pela Universidade Federal do Rio Grande do Sul - Porto Alegre (UFRGS). Docente do Programa de Pós-Graduação em Linguística da Universidade Federal de Santa Catarina (UFSC). Contato: felicio.margotti@ufsc.br.

*** Graduanda (2020) em Letras Língua e Literatura Portuguesa pela Universidade Federal do Amazonas (UFAM) - Campus de Manaus. Contato: ilnaufam@gmail.com.

\section{Resumo:}

Este artigo aborda a formação de palavras com os adjetivos de origem tupi açu e mirim, no português amazônico. O corpus para a análise foi constituído a partir da leitura de livros e dicionários, nos quais constam as formações por composição com esses adjetivos. Para os propósitos da pesquisa, a fundamentação teórica é baseada no modelo da Morfologia Gerativa (ARONOFF, 1976; SPENCER, 1991; ROCHA, 2008; BASÍLIO, 2009), a fim de que fosse possível a construção de regras aplicáveis às bases que esses adjetivos selecionam. Os resultados mostram a existência de formações por composição, principalmente, e a aplicação da Regra de Análise Estrutural (RAE) e da Regra de Formação de Palavra (RFP). Algumas construções não possuem entradas em dicionários e outras não caracterizam o processo de formação por composição. Conclui-se que existe uma extensa lista de palavras formadas com - açu e com mirim incorporadas ao português brasileiro, demonstrando que são étimos bastante produtivos na formação de palavras compostas e, por vezes, na formação de palavras por derivação.

\section{Palavras-chave:}

Formação de palavras. Português amazônico. Morfologia Gerativa.

Signum: Estudos da Linguagem, Londrina, v. 22, n. 2, p. 55-71, ago. 2019

Recebido em: 16/09/2019

Aceito em: 14/03/2020 


\section{Formação de Palavras com Adjetivos de Origem Tupi no Português Amazônico}

Orlando da Silva Azevedo; Felício Wessling Margotti; Ilna Kelly Ferreira dos Santos

\section{CONSIDERAÇõES INICIAIS}

Neste trabalho, catalogamos palavras formadas pelos adjetivos aç, que significa "grande", e mirim, que significa "pequeno" (CUNHA, 1999), ambos de origem tupi. Participaram da constituição do corpus os dados constantes em livros e dicionários sobre a fauna e a flora regional amazonenses.

Nosso propósito foi verificar se as palavras formadas com adjetivos de origem tupi possuem entradas nos dicionários Aurélio (FERREIRA, 2009) e Houaiss (HOUAISS et al., 2009), e analisar as bases que esses sufixos selecionam. Trabalhamos com o modelo da Morfologia Gerativa (ARONOFF, 1976; SPENCER, 1991; ROCHA, 2008; BASÍLIO, 2009), que analisa os aspectos morfológicos a partir da competência linguística do falante, que, por sua vez, é capaz de formar novos vocábulos e de reconhecer a estrutura das palavras. Aplicamos na análise das formações por composição os conceitos de Análise de Regra Estrutural (RAE) e de Regra Formação de Palavra (RFP), geralmente aplicados ao processo de formação por derivação, em que participam afixos (prefixos e sufixos).

\section{Natureza da Pesquisa}

Para a realização deste estudo, catalogamos formações substantivas envolvendo os adjetivos de origem tupi açu e mirim, e suas variantes. O material investigado, conforme descrito anteriormente, foram os livros de literatura amazônica, dicionários etimológicos e os dicionários Aurélio (FERREIRA, 2009) e Houaiss (HOUAISS et al., 2009). Trata-se, portanto, de uma pesquisa bibliográfica, a partir da qual houve a catalogação das formações de palavras envolvendo os adjetivos estudados. Constituímos assim uma amostra, na qual foi possível verificar a existência de Regra de Análise Estrutural e a aplicação de Regra de Formação de palavras.

Esta pesquisa tem caráter qualitativo porque, conforme Callado et al. (2013, p. 33),

O enfoque qualitativo também se guia por áreas ou temas significativos de pesquisa. No entanto, ao contrário da maioria dos estudos quantitativos, em que a clareza sobre as perguntas de pesquisa e as hipóteses devem vir antes da coleta e da análise dos dados, nos estudos qualitativos é possível desenvolver perguntas e hipóteses antes, durante e 
depois da coleta e da análise dos dados. Geralmente, essas atividades servem para primeiro descobrir quais são as perguntas de pesquisa mais importantes, depois para aprimorá-las e respondê-las. A ação indagativa se move de maneira dinâmica em ambos os sentidos: entre os fatos e sua interpretação, e é um processo mais 'circular' no qual a sequência nem sempre é a mesma, ela varia de acordo com cada estudo específico.

Ainda segundo esses autores, a pesquisa qualitativa é voltada para a exploração, a descrição e o entendimento do fenômeno em estudo. Uma de suas características é a utilização de dados sem medição numérica para o descobrimento e aprimoramento de perguntas de pesquisa no processo de interpretação do fenômeno em estudo.

Além do caráter qualitativo, este estudo também possui um enfoque quantitativo, caracterizando o método que "utiliza a coleta de dados para testar hipóteses, baseando-se na medição numérica e na análise estatística para estabelecer padrões e comprovar teorias" (CALLADO et al., p. 30). Por isso, contabilizamos todas as formações encontradas nos livros sobre a flora e a fauna regionais amazônicas, as quais verificou-se se possuíam entradas em dicionários de língua portuguesa.

\section{A Regra de Análise Estrutural (RAE) e Regra de Formação de Palavra (RFP)}

Segundo o modelo teórico do Gerativismo (CHOMSKY, 1997), todo falante possui competência linguística para formar novas palavras na língua. De acordo com essa concepção, o falante consegue, a partir de uma base, derivar, justapor ou aglutinar novas formações. Essa propriedade inata, caracterizada como recursividade, permite ao falante perceber a existência de uma base padrão ou de uma palavra-base da qual podem surgir produtos como substantivos, adjetivos ou verbos, caracterizando, assim, o processo como sendo derivacional, através do acréscimo de prefixos e sufixos, ou composicional, por meio da combinação de bases autônomas ou não.

Ao reconhecer a base e seus acréscimos, o falante faz uso da Regra de Análise Estrutural (RAE) que, de acordo com o modelo teórico da Morfologia Gerativa, é representada da seguinte forma: $[\mathrm{X}] \mathrm{a}>[\mathrm{X}] \mathrm{a}[\mathrm{Y}] \mathrm{b}$ (onde "X" é a base primitiva; "a" é classe gramatical da base; "Y" é o afixo que seleciona a base e; "b" é o produto da junção do afixo com a base para formar uma nova palavra com mudança de classe gramatical ou formar uma nova palavra sem mudar a classe gramatical (ARONOFF, 1976; SPENCER, 1991).

A RAE é pré-condição para a criação de uma Regra de Formação de Palavra (RFP), que se define por uma relação semântico-categorial unitária, mas não necessariamente unicategorial (RIO-TORTO, 1998). Quando o falante produz novos vocábulos ao utilizar, por exemplo, um prefixo ou sufixo, está fazendo uso de uma RFP.

Exemplificamos com o léxico amazônico a aplicação da RFP, envolvendo as formações com o sufixo - rana, também de origem tupi, que foi documentado na tese 
de Azevedo (2013), cujo estudo abordou aspectos dialetais do português amazônico. As formações abacaxirana, melanciarana e uixirana referem-se a frutas regionais encontradas nas matas de igapó, as quais são comestíveis apenas para alguns animais, como os peixes regionais. Assim, temos a seguinte representação:

$$
\begin{aligned}
& \text { Exemplos } 1 \\
& {[\mathrm{X}] \mathrm{S}>[[\mathrm{X}] \mathrm{S}-\text { rana }] \mathrm{S}} \\
& \text { Exemplo a: }[\text { abacaxi }] \mathrm{S}>[[\text { abacaxi }] \mathrm{S}-\text { rana }] \mathrm{s}=[\text { abacaxirana }] \mathrm{s} \\
& \text { Exemplo b: }[\text { melancia }] \mathrm{S}>[[\text { melancia }] \mathrm{S}-\text { rana }]_{\mathrm{s}}=[\text { melanciarana }] \mathrm{s} \\
& \text { Exemplo c: }[\text { uixi }] \mathrm{S}>[[\text { uixi }] \mathrm{S}-\text { rana }]_{\mathrm{s}}=[\text { uixirana }] \mathrm{s}
\end{aligned}
$$

Nos Exemplos 1, as bases substantivas abacaxi, melancia e uixi mais o sufixo -rana formam novos substantivos (AZEVEDO; MARGOTTI, 2012).

Para Aronoff (1976), a RFP se aplica no âmbito lexical, fazendo referências às propriedades fonéticas, semânticas e sintáticas das palavras.

\section{O Processo Derivacional}

$\mathrm{Na}$ formação de palavras por derivação na língua portuguesa são observados os parâmetros estabelecidos a partir da combinação entre palavras e afixos já existentes no idioma. Na perspectiva da Morfologia Gerativa, o falante, mesmo sendo iletrado, conhece as regras de formação de palavras e, por isso, é capaz de criar novas palavras a partir dos recursos linguísticos previstos pela gramática da língua. Tal mecanismo, a título de ilustração, é usado por crianças e por adultos no uso de formas como "morração" em vez de morte; "desmorreu" em vez de ressuscitar, "descubrição" em vez de "descobrimento" etc. Ou, na flexão, constata-se o uso de formas como "reia" para o feminino de rei, em vez de rainha; "boia" para o feminino de boi, em vez de vaca; "fazi" em vez de faz etc.

Consideramos que as bases mais comuns a que os sufixos se fixam são substantivos, adjetivos e verbos (BASÍLIO, 2009), sendo que a maioria dos processos de formação de palavras por sufixação muda a classe gramatical da base, e a produtividade de cada sufixo tem a ver com o tipo de base(s) que seleciona. Por exemplo, o sufixo $X-v e l$ forma adjetivos combinando-se com verbos transitivos diretos: amar + -vel $=$ amável, estimar $+-v e l=$ estimável, louvar $+-v e l=$ louvável, e rejeita outras bases como o substantivo homem $+-v e l=*$ homemvel e o adjetivo beleza $+-v e l=*$ belezável. Se a estrutura morfológica for um verbo em $X$-iz̧ar, o sufixo correspondente à forma nominalizada será -ção; por outro lado se for $X$-ecer, o sufixo atuante na formação da nova palavra será - mento (BASÍLIO, 2009).

Além disso, conforme o contexto de uso, o falante pode priorizar a formação de palavras a partir da escolha das bases e de sufixos existentes na língua. Logo, as condições 
de produção de cada sufixo têm a ver com o contexto em que ele é empregado, ou seja, com o ambiente discursivo, pragmático ou cultural que envolve o usuário da língua (BASÍLIO, 1980). Por exemplo, tomemos as realizações do vocábulo "não" na linguagem informal e na linguagem formal: na linguagem falada informal, o usuário faz as realizações como "não", " não é", "né" e "nuB" com função adverbial, como partícula enfática para realçar a negação ou para pedir confirmação do interlocutor como em "- Ele foi pra festa? - Nũ foi não, né?” etc.; já na linguagem formal falada ou escrita, com o mesmo vocábulo "não", além do emprego adverbial ou em outras funções discursivas, têm-se construções tipo "não-lucrativo", "não-didático", "não-jurídico", "não-escrito", nas quais o "não" tem a função de servir como prefixo negativo ao selecionar bases adjetivas, formas participiais com função adjetiva, e se constitui de uma forma fixa e recorrente, já consolidada na língua portuguesa como elemento de formação de palavra (ALVES, 2002, p. 91-97).

O advérbio "não" passa a exercer outra função gramatical, negando o significado expresso pela base, selecionado bases substantivas, adjetivas e verbais (ALVES, 2002, p. 99).

Os sufixos, portanto, possuem características específicas e em geral selecionam bases específicas, podendo mudar ou não a classe gramatical da palavra derivada. Também são mais produtivos em determinados ambientes discursivos, pragmáticos ou culturais, onde há a necessidade de nomeação de novos referentes.

\section{O Processo Composicional}

A composição é outro processo de formação de palavras muito produtivo em língua portuguesa, pois contribui continuamente para a formação de novos vocábulos e ocorre quando são aglutinados ou justapostos dois ou mais radicais, formando novas palavras com significados diferentes das palavras que participaram do processo. Para Rio-Torto (1998), a composição se define pela concatenação de no mínimo duas bases mais ou menos autônomas. Exemplos de Azevedo (2013):

$$
\begin{aligned}
& \text { Exemplos } 2 \\
& \text { pau }+ \text { de }+ \text { bico }=\text { pau-de-bico } \\
& \text { vai }+ \text { quem }+ \text { quer }=\text { vai-quem-quer } \\
& \text { espanta }+ \text { mole }=\text { espanta-mole }
\end{aligned}
$$

\footnotetext{
${ }^{1}$ Instrumento de pesca, que pode ser feito com uma vara de madeira a ser apontada em uma das pontas.

${ }^{2}$ Nome dado ao lugar onde o caboclo do Juruti-Velho (PA) produz a farinha de mandioca.

${ }^{3}$ Outra denominação para o lugar onde se produz farinha no Juruti-Velho.
} 
Como já caracterizado, a composição é um processo de formação de novas palavras pela aglutinação ou justaposição de vocábulos já existentes ou de bases não autônomas, ou entre uma base autônoma e outra não autônoma e vice-versa. Esse processo caracteriza o princípio da economia linguística, cuja função é a de não sobrecarregar o sistema linguístico com excesso de palavras novas. Enquanto nos processos derivacionais por prefixação, sufixação e parassíntese registra-se um único semantema (raiz, também denominada de radical primário, entre outras designações), nos processos de composição ocorrem dois ou mais semantemas (duas ou mais bases).

$\mathrm{Na}$ língua portuguesa, na composição de novas palavras por aglutinação ou justaposição, participam preferencialmente bases livres, que são vocábulos formais que podem ser pronunciados isoladamente e, mesmo assim, expressam ideias e formas dependentes como artigos, preposições, algumas conjunções e pronomes oblíquos átonos. A estrutura dos compostos é bastante variada, como se demonstra a seguir:

a) substantivo + substantivo: tamanduá-bandeira, peixe-boi, papel-moeda;

b) substantivo + preposição + substantivo: pé-de-vento, pai-de-família, arroz-de-festa;

c) substantivo + adjetivo (ou vice-versa): amor-perfeito, aguardente, belas-artes, alto-forno;

d) adjetivo + adjetivo: luso-brasileiro, tragicômico, surdo-mudo;

e) numeral + substantivo: terça-feira, três-marias, trigêmeo;

f) pronome + substantivo: meu bem, Nosso Senhor, Vossa Excelência;

g) verbo + substantivo: lança-perfume, beija-flor, guarda-roupa;

h) verbo + verbo (ou verbo + conjunção + verbo): corre-corre, vaivém, leva-e-traz;

i) advérbio + substantivo (ou + adjetivo, ou + verbo, ou + pronome + verbo): benquerença, sempre-viva, não-machadiana, bem-querer, vangloriar-se, malmequer;

j) verbo + advérbio: pisa-mansinho, ganha-pouco;

k) grupo de vocábulos e construções oracionais: Deus-nos-acuda, Maria-vai-comas-outras, o mama-na-égua.

Baseado nisso, analisaremos as particularidades das formas -açu e -mirim, de origem tupi, que contribuíram acentuadamente na formação de palavras no português regional amazonense, principalmente.

\section{Adjetivos de Origem Tupi: $A C ̧ U$ e $M I R I M$}

Na primeira carta, ${ }^{4}$ datada de 21 de novembro de 1751, o Capitão-General Francisco Xavier de Mendonça Furtado, do Pará, escreve ao irmão Marquês de Pombal,

\footnotetext{
${ }^{4}$ Gênero textual usado à época como instrumento de comunicação.
} 
em Portugal, sobre os problemas que surgiram na Amazônia portuguesa. Nessa carta, há o registro das formas $A c ̧ u$ e Mirim:

Para V. Ex $x^{a}$ poder compreender bem este absurdo, que na verdade se faz incrível, é preciso saber que a palavra Tupana na tal gíria é Deus; as duas Açu e Mirim é o mesmo que grande e pequeno, e são os ditos índios educados para explicarem Deus dizendo Tupana Açu Deus grande; e os santos, suas imagens e verônicas Tupana Mirim = Deus pequeno; e isto que eles dizem que é um modo de explicar, por não haver na tal língua a palavra Santo, sempre dado por elemento de religião a uma gente silvestre, lhes forma uma idéia de muitos deuses, o que é totalmente defendido e oposto à verdadeira fé que nos ensina a Igreja Católica (MENDONÇA, 2005, p. 113, itálicos nossos).

O trecho descreve a dificuldade em relacionar referentes extralinguísticos próprios dos indígenas com os de origem portuguesa, pois são realidades socioculturais e linguísticas diferentes. Cunha (1999, p. 211), em seu Dicionário Histórico das Palavras Portuguesas de Origem Tupi, apresenta trechos de obras da literatura brasileira onde há o registro das formas açu e mirim:

a1696 G. Matos Obras (ed.1969, II, 459): À vista dêste Alfaiate disse o Cabido espantando, somos nós gatos mirins que inda agora engatinhamos.

1868 J. M. Macedo Memórias do meu tio II, vii1868:[...] mirim é adjetivo guarani que não entra no dicionário do genio progressista da nossa idade: todas as entidades mirins são esmagadas pelas locomotivas da moderna civilização. 1894 TAUNAY O Encilhamento I. xxix, 2012: [...], como rosado presunto, de meio, sem mais Chopins e Chapecós, Pepirys e Santo Antônio mirins ou guaçus, aquelle bravio território, tantos decennios, litigioso [...]

1946 GUIMARÃES ROSA Sagarana 226: Só que eu acendo outro cigarro, por causa dos mil mosquistos, que são corja de demônios mirins.

Percebemos, nesses trechos, que era recorrente o uso da forma mirim e aç como adjetivos para quantificar substantivos sem, contudo, formar palavras compostas.

Segundo Dietrich e Noll (2010), o Houaiss (HOUAISS et al., 2009) possui 273 formações brasileiras com açu e 94 com mirim. Além disso, os pesquisadores consideram essas duas formas ora como pseudossufixos, ora como sufixos e ora como adjetivos. Rocha (2008) usa a terminologia "sufixóides, ou pseudo-sufixos", para caracterizar sequências fônicas não recorrentes, que selecionam bases livres mudando o sentido da base primitiva.

Para ser um sufixoide, não deve haver a recursividade, ou seja, ter a capacidade de formar novas palavras como, por exemplo, o que acontece com a sequência fônica -ebre em casebre, pois não aparece em nenhuma outra palavra em português. Assim, são sufixoides: bicho/bichano, urina/urinol, pé/pedestre, curso/cursilho, serra/serrota (ROCHA, 2008, p. 121).

Entretanto, veremos que os adjetivos açu e mirim comportam-se como sufixos devido à gama de formações em língua portuguesa, envolvendo bases de origem tupi. 


\section{Palavras de Origem Tupi com $A C ̧ U$}

A língua portuguesa tomou emprestada do tupi a forma gwa'su, que significa grande, com a escrita guaçu. Em 1928, a forma guaçu era registrada como guassú na obra Macunaíma, de Mário de Andrade. Na versão da obra de 2017 podemos visualizar a grafia guacu:

- Si... si... si a boboiuna aparecesse eu... eu matava ela!

Então se escutou um urro guaçu e Capei veio saindo d'água. E Capei era a boiuna. Macunaíma ergueu o busto relumeando de heroísmo e avançou pro monstro (ANDRADE, 2017, p. 30).

Quanto à forma $a c ̧ u$, esta possui outras variantes: no tupi é -wa'su, e no português é -uaçu, com redução do grupo iniciado por consoante velar sonora -gw- à semivogal posterior arredondada -w-, formando-se o ditongo -wa-em posição pretônica. A forma -a'su, do tupi, corresponde à forma -açu, com queda da semivogal, no português.

Registra-se também a variante alomórfica do tupi - $u^{\prime} s u$, correspondente a -uçu no português, havendo mudança de $-a$ - para $-u$-, em relação às diferenças de vogais pretônicas, caracterizando uma espécie de harmonia vocálica ou assimilação que, em contextos formais favoráveis, tende a se aproximar do timbre da vogal tônica final.

Surge a partir do século XVI em palavras de origem tupi, ao mesmo tempo em que perdura seu uso como adjetivo, que quantifica a base como sendo algo "grande".

Na obra Ubirajara, de José de Alencar (2014, ed. Kindle), há o registro da curumim-guassú, que significa menino grande. Em Iracema, do mesmo autor, o personagem e chefe indígena é chamado de Jaguaraçu (2018, ed. Kindle).

Enumeram-se, na sequência, formações que envolvem nomes de peixes: acaráaçu, acaranaçu, ${ }^{5}$ саranaçu, ${ }^{6}$ acariaçu, aiaraçu, guaibicuaraçu, tatapuiaçu (CUNHA, 1999, p. 285); da culinária: bejuaçu; de aves: ajuruaçu, arapaçu, arataiaçu, atingaçu, atiuaçu, guiranaçu (p. 143), guiraguaç (p. 306), guiraguaçuberaba, nambuaçu, picaçu, uraçu, sanbaçu, sanbaço-de-encontro, sanhaguira e sanhaç-verde, sairaçu, mutum-açu, Abijaguaģ (p. 42); de mamíferos: acutipuruaçu, aguaraçu (GLOSSÁRIO..., 2018, ed. Kindle), suaçu; de répteis: araracangaçu, iuraracangaçu, jiboiaçu, teinaçu (CUNHA, 1999, p. 288), boiaçu, tamanduá-açu; de vermes ou anelídeos: minhocaçu, minhocuçu, tungaçu (р. 299); de plantas: aguaçu, aguaraibá-guaçu, aguaraquiá-açu, andá-açu, anilaçu, aningaçu, auaçu, babaçu, bauaçu, buiuçu, саиaçu, соас̧u, ${ }^{10}$ саá-açu, pixiricuçu, ${ }^{11}$

\footnotetext{
${ }^{5}$ Variante coloquial de acará-açu, o peixe regional.

${ }^{6}$ Variante coloquial de acará-açu, o peixe regional.

${ }^{7}$ Variante de guiaraguaçu.

${ }^{8}$ Possui as variantes boiaçu, boiçu, boioçu e boinçu.

${ }^{9}$ Babaçu possui outras variantes como baguaçu, aguaçu, auaçu, banaçu.

${ }^{10}$ Variante de canaçu sem registro em dicionários.

${ }^{11}$ Sem registro nos dicionários pesquisados.
} 
samambaiaçu, sambambaiaçu, uaça̧u (p. 303), carauaçú (WITTMANN et al., 2010, p. 84), арарас̆ (CARREIRA, 2004, p. 27); de frutas: cupuaçu, ingá-açú (WITTMANN et al. 2010, p. 119), tatararaçu, taperibá açu (CARREIRA, 2004, p. 146), tucum-açu, tucumã-açu (BARBOSA et al., 2001, p. 13), marajá-açu (p. 17), bacaba-açu, bacabaçu; de insetos: aranbaçu, nhanduaçu (CUNHA, 1999, p. 220); de rio: Coaçu, ${ }^{12}$ de meio de transporte: Igaraçu; de topônimos: Mogi-Guaçu, Itajaí Açu, Aracaçu, Coaçu. ${ }^{13}$

Além disso, encontramos formações com a variante uçu em nomes: de plantas: ubuç, buçu, uхipuç; viruç, taquaruçu, сораibuçu (BARBOSA, 2001, p. 113); de réptil: boiuçu; de ave: tucanucu.

A formação com -aço prestou-se, por exemplo, para a formação das seguintes palavras no campo semântico aves: sanhaço, sanhaço-amarelo, sanhaço cinzento, sanhaço-daamazônia, sanbaço-da-serra, sanhaço-de-coqueiro, sanhaço-de-fogo, sanbaço de mamoeiro, sanhaço-docampo, sanhaço-frade, sanhaço pardo, sanhaçotinga.

Foram encontradas, também, formações com a variante guaçu para inseto: miringuaçu; plantas: auaí-guaçu, caaguaçu, carandaguaçu (CUNHA, 1999, p. 103), carobaguaçu, jequiitiguaçu, tarumã-guaçú, ${ }^{14}$ tarumã-guaçu (WITTMANN et al., 2010, p. 240); culinária: beijuguaçu; instrumento de sopro: membiguaçu (CUNHA, 1999, p. 209); peixes: canapuguaçu, guacariguaçu, amoreguaçu (p. 49), guacariguaçu; aves: nambuguaçu, inhambuguaçu, inambuguaçu, inamuguaçu, nambuguaçu, nhambuguaçu, nhanduaguaçu, ${ }^{15}$ saíra-guaçu, atinguaçu, tinguaçu, jacuguaçu, sabiá-guaçu; frutas: carandáguaçu, baguaçu (GLOSSÁRIO..., 2018, ed. Kindle), aguaçu; réptil: boiguaçu.

Algumas formações não possuem entrada nos dicionários Houaiss (HOUAISS et al., 2009) e Aurélio (FERREIRA, 2009), tais como: curumim-açu, curumim, guassú, apapaçu etc.

\section{Palavras de Origem Tupi com Mirim}

Mirim é um adjetivo de origem tupi mi r̃̆, que significa "pequeno", sendo, às vezes, reduzido a -im e $-i$ (HOUAISS et al., 2009, p. 1297). Baseando-nos na definição encontrada em Houaiss e no Dicionário Histórico das Palavras Portuguesas de Origem Tupi (CUNHA, 1999, p. 211), a variável seria (mi' $\tilde{r l}) \rightarrow[$ mirim $] \rightarrow[$ rim ou $\tilde{n}] \rightarrow[\mathrm{im}] \rightarrow[\mathrm{i}]$, ou seja, a forma mir̃ evoluiu para mirim, com acréscimo de $m$, paragoge ou epítese; depois sofre a perda de mi, fenômeno esse conhecido como aférese, chegando à forma rim ou ri; sofre nova aférese, resultando em im; e, por último, ocorre a apócope do m,

\footnotetext{
${ }^{12}$ Rio do estado do Ceará, sem registro nos dicionários pesquisados.

${ }^{13}$ Nome de bairro da cidade Fortaleza.

${ }^{14}$ Sem registro nos dicionários pesquisados.

${ }^{15}$ Sem registro nos dicionários pesquisados.
} 
fixando-se em $i$. Portanto, podemos encontrar formações com essas quatro variantes, sendo mais fáceis de identificar nas palavras a forma [mirim] do que as demais, que se aglutinam com a base que selecionam.

Encontramos diferentes formações com a variante im para: meio de transporte: igaratim; mesmo nome: xarapim; nome de tribo indígena: tupiniquim; cupinzeiro: tapecuim; cor de cabelo: pixaim; odor de peixe: pituim; referir-se a menino: curumim, colomim, columim; referir-se a menina: cunhantaim; culinária: cauim, caxirim, piracuim; peixes: camurim, camuripim, camurupim, camarupim, canjurupim, mandim, surubim; plantas: bogarim, cabuim, capim, catuquim, cumbarim, cunabim, japanim, jenipapim, juritiubim, muritim, pixurim, sambacuim, ubim, xaxim; insetos: aratim, arancim, iratim, cabamoatim, camoatim, iraxim, itapecuim, itapicuim, catuquim, maringuim, maruim, meruim, miruí, miruim, muruim, micuim, mucuim, tapicuim, timicuim; aves: apacanim, inapacanim, cajubim, cujubim, cutucurim, jacamim, japacanim, japiim, japim, mutumboicinim, nhapim, puxicaraim, tururim, tururuim, uiruucotim; instrumento funerário: camotim, camucim; mamíferos: aguaraxaim, guaraxaim. graxaim, guaximim, buriquim, cuim, guaraparim, saguim, sauim, soim, sonbim, xauim, jurumim, tamanduá-mirim; tubérculo: aipim, ${ }^{16}$ impim, ipim; réptil: jabutim; molusco: maçunim; embarcação: maracatim.

As construções envolvendo a variante mirim formam adjetivo: mirim-docense; nome: curumim mirim (ALENCAR, 2012, ed. Kindle); nomes de crustáceo: potimirim, rerimirim (CUNHA, 1999, p. 252); nomes de aves: inhambumirim, ipecumirim; nomes de plantas: abatimirim, ibamirim, tarumã-mirim, guamirim (p. 137), guamirim-felpudo, irimirim, airimirim, itaubarana-mirim (WIT'TMANN et al., 2010, p. 178), juá-mirim, jutaí-mirim, ${ }^{17}$ ubi-mirim (BARBOSA et al., 2001, p. 59), cajá-mirim (WITTMANN et al., 2010, p. 203); nomes de insetos: cabamirim, tujumirim, mirim-guaçu, mirim-pintada, mirim-preguiça, mirim-rendeira; nomes de acidentes geográficos: Uxié-mirim (MENDONÇA, 2005, p. 348), Paraná-mirim, Uxiemirim (p. 60); topônimos: Guarijuba-mirim ${ }^{18}$ (p. 98), Parati Mirim, Lagoa Mirim, Itajaí Mirim, Gujará-Mirim, Mirim Doce (FERREIRA, 2009, p. 1337), Ibirajubamirim (MENDONÇA, 2005, p. 237); nome de frutas: ingá-mirim, buriti-mirim (BARBOSA et al., 2001, p. 89), buritimirim (HOUAISS et al., 2009, p. 338), bacaba-mirim (p. 102), bacabamirim, araçá-mirim; nome de mamífero: quatimirim.

$\mathrm{O}$ adjetivo mirim pode se antepor à base como se pode visualizar em: mirim-gucu/ miringucu, mirim-pintada, mirim-preguiça, mirim-rendeira, Mirim Doce, mirim-docense etc.

A forma $-i$ participa da formação de alguns vocábulos da língua portuguesa, cujas bases costumam ser de origem tupi. Essa variante expressa particularmente a noção

\footnotetext{
${ }^{16}$ Variantes aipi, aimpim, impim e ipim.

${ }^{17}$ Sem entrada nos dicionários pesquisados.

18 "Fazenda Guarijuba-Mirim: não consta do mapa da Companhia de Jesus, de 1752, da Biblioteca Eborense, publicado por João Lúcio, em Os Jesuítas no Grão-Pará, e por Serafim Leite, no vol. IV, de sua História da Companhia de Jesus no Brasil, sendo a publicação de João Lúcio, bem melhor. Nesse mapa os jesuítas não incluíram todas as suas fazendas da região Amazônica."
} 
de "pequeno", "diminuto", equivalente ao sufixo -inho, inha, -zinho, -zinha em português. Mello (2003, p. 43, 53) afirma que -i é uma forma contraída de miri, "pequeno", que primeiramente se contraiu em $-r i$ para depois passar a $-i$.

As formações com $-i$ envolvem nomes de graveto de planta: sacaí; odor de peixe: pituí, carataí, piraí; de aves: inhambui, nhandui, tucunui, araguaí, caracaraí, picuí, saí, socoí; de frutas: cupui (AGUIAR; FREITAS, 2005, p. 39); de mamíferos: saui, tatui; de culinária: cauí, juquiraí, piracuí; de plantas: carandaí, caranaí, curuaí, tarumaí, araçaí, cajuí, açaí, açai-da-várzea, açai-solitário, aguai, agai, ajaraí, apuí, apui-da-folba-larga, apurui, cambui, cupuai, сираi, curupai, curupicaí, embirataí, guajaraí, guapuí, japicaí, jataí, jatai-mondé, jutai-café, jutai pororoca, puruí, seringaí, louro-inamui (WITTMANN et al., 2010, p. 53), inbamui (p. 53), óleo-de-inhamuí (p. 53), jaraí (p. 221); de insetos: nhanduí (CUNHA, 199, p. 220), enxuí, iraí, maruí, muruí, tapiaí; de turbérculo: mandiocai $i^{19}$ de topônimos: Uraí, ${ }^{20}$ Mucajaí. ${ }^{21}$

As condições de produção dos adjetivos açu e mirim estão relacionadas ao ambiente amazônico, principalmente com palavras formadas dentro do domínio semântico "leguminosas", "árvores/arbustos", animais e acidentes geográficos. E as condições de produtividade estão relacionadas à base que essas formações selecionam, incluindo adjetivos, substantivos e formas participiais com função de adjetivo, cujo produto será sempre um substantivo.

\section{Aplicação da Regra de Análise Estrutural (RAE) e da Regra de Formação de Palavra (RFP)}

A Regra de Análise Estrutural com formações em açu e mirim pode ser formulada da seguinte maneira: $[[\mathrm{X}] \mathrm{s}] \rightarrow\left[[\mathrm{X}] \mathrm{s}(\mathrm{açu})_{\mathrm{adj}}\right]_{\mathrm{s}}$ e $[\mathrm{X}] \rightarrow\left[[\mathrm{X}] \mathrm{s}(\text { mirim })_{\text {adj }}\right]_{\mathrm{s}}$.

Quando formamos palavras com essas estruturas, estamos fazendo uso da Regra de Formação de Palavras (BASÍLIO, 1980). Assim, teremos a RFP com -açu, envolvendo bases substantivas:

$$
\begin{aligned}
& {[\mathrm{X}] \mathrm{s} \rightarrow\left[[\mathrm{X}]_{\mathrm{s}}(\mathrm{açu})_{\mathrm{adj}}\right]_{\mathrm{s}}} \\
& \text { [jacaré }] \mathrm{s} \rightarrow\left[[j \text { acaré }] \mathrm{s}(\mathrm{açu})_{\text {adj }}\right] \mathrm{s}=[\text { jacaré-açu }]_{\mathrm{s}} \\
& \text { [cupu }] \mathrm{s} \rightarrow\left[[\mathrm{cupu}]_{\mathrm{s}}(\mathrm{açu})_{\text {adj }}\right] \mathrm{s}=[\mathrm{cupu}-\mathrm{açu}]_{\mathrm{s}} \\
& \text { [itapéua }] \mathrm{s} \rightarrow\left[[\text { itapéua }]_{\mathrm{s}}(\text { açu })_{\text {adj }}\right] \mathrm{s}=[\text { itapéuaçu }]_{\mathrm{s}}
\end{aligned}
$$

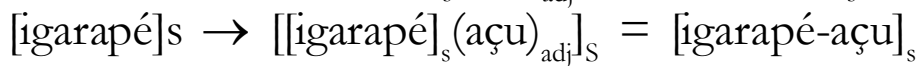

Os produtos da formação, nesses exemplos, são substantivos. O adjetivo açu também seleciona bases verbais. Por exemplo:

\footnotetext{
${ }^{19}$ Sem registro nos dicionários utilizados na pesquisa.

${ }^{20}$ Sem registro nos dicionários pesquisados.

${ }^{21}$ Sem registro nos dicionários pesquisados.
} 


$$
\begin{aligned}
& {[\mathrm{X}] \mathrm{s} \rightarrow\left[[\mathrm{X}] \mathrm{s}(\mathrm{accu})_{\text {adj }}\right]_{\mathrm{s}}} \\
& {[\text { aguar }] \mathrm{v} \rightarrow\left[[\mathrm{X}] \mathrm{v}(\text { açu })_{\text {adj }}\right]_{\mathrm{s}}=[\text { aguaraçu }]_{\mathrm{s}}} \\
& {[\text { andá }] \mathrm{v} \rightarrow\left[[\mathrm{X}] \mathrm{v}(\text { açu })_{\text {adj }}\right]_{\mathrm{s}}=[\text { andá-açu }]_{\mathrm{s}}}
\end{aligned}
$$

Toda RFP se correlaciona com a RAE, sendo, portanto, aplicável às formações com aç e mirim.

$\mathrm{Na}$ formação com mirim, temos para $\left.[\mathrm{X}] \mathrm{s} \rightarrow[\mathrm{X}] \mathrm{s}(- \text { mirim) })_{\text {adj }}\right] \mathrm{s}$ a seguinte Regra de Formação de Palavra (RFP):

[jacaré $] \mathrm{s} \rightarrow\left[[j \text { acaré }] \mathrm{s}(\text { mirim })_{\text {adj }}\right]_{\mathrm{s}}=[$ jacaré-mirim $] \mathrm{s}$

[cupu $] \mathrm{s} \rightarrow[$ cupu $] \mathrm{s}-\mathrm{i}] \mathrm{s}=$ [cupuí]

[paraná]s $\rightarrow$ [paraná]s $\left.(\operatorname{mirim})_{\text {adj }}\right]_{\mathrm{s}}=$ [paraná-mirim $] \mathrm{s}$

[igarapé $] \mathrm{s} \rightarrow\left[[\text { igarapé }] \mathrm{s}(\text { mirim })_{\text {adj }}\right]_{\mathrm{s}}=$ [igarapé-mirim]s

Em se tratando de mirim, tem-se também a regra de formação de palavra invertida, por exemplo:

a. $\left.[\text { mirim }]_{\text {alj }} \rightarrow\left[[\text { mirim }]_{\text {adj }} \text { guaçu }\right)_{a d j}\right]_{s=}[\text { mirim-guaçu/miringuaçu }]_{S}$

b. $[\text { mirim }]_{\text {aljj }} \rightarrow\left[[\text { mirim }]_{\text {adj }} \text { preguica }\right]_{\mathrm{s}}=[\text { mirim-preguiça }]_{\mathrm{S}}$

c. $\left.[\text { mirim }]_{\text {adj }} \rightarrow\left[[\mathrm{mirim}]_{\text {adj }} \text { pintada }\right)_{\text {part }}\right]_{\mathrm{s}=}[\text { mirim-pintada }]_{\mathrm{S}}$

d. $[\text { mirim }]_{\text {alf }} \rightarrow\left[[\text { mirim }]_{\text {adj }}\right.$ doce $\left.)\right]_{\mathrm{s}}=[\text { Mirim Doce }]_{\mathrm{S}}$

e. $\left.[\text { mirim }]_{\text {alj }} \rightarrow\left[[\mathrm{mirim}]_{\text {adj }} \text { docense }\right)_{a \mathrm{ajj}}\right]_{\text {aljj }}=[\text { mirim-docense }]_{\mathrm{ADJ}}$

Nesses exemplos, mirim seleciona: em a, o adjetivo guaç, produzindo um substantivo composto, mirim-guacu/miringuacu; em b, o substantivo preguiça, produzindo um substantivo composto, mirim-preguica; em c, o particípio ou forma nominal pintada, produzindo um substantivo composto, mirim-pintada; em d, o adjetivo doce, produzindo um substantivo composto, Mirim Doce; e em e, o adjetivo docense, produzindo um adjetivo composto mirim-docense, formado a partir de dois adjetivos. O produto envolvendo os compostos formados com mirim serão substantivos, exceto aqueles relativos à toponímia, pois serão adjetivos.

Rocha (2008, p. 42-43) afirma que devem ser feitas três observações sobre a RAE:

a) O conceito de RAE está necessariamente ligado ao estabelecimento de relações paradigmáticas, o que ocorre com as formações com açu e mirim, respectivamente:

$\begin{array}{ll}\text { itapéua } \rightarrow \text { itapéuaçu } & \text { paraná } \rightarrow \text { paraná-mirim } \\ \text { igarapé } \rightarrow \text { igarapé-açu } & \text { igarapé } \rightarrow \text { igarapé-mirim } \\ \text { cupu } \rightarrow \text { cupuaçu } & \text { cupu } \rightarrow \text { cupuí } \\ \text { acará } \rightarrow \text { acará-açu } & \text { acará } \rightarrow \text { acaraí } \\ \text { jacaré } \rightarrow \text { jacaré-açu } & \end{array}$


No rol exemplificativo acima, mudamos a base, que possui significado diferente, e as formas açu, mirim e $i$ podem ser encaixadas no eixo paradigmático, resultando em formações substantivas por composição. Ressaltamos que as formações envolvendo a variante $-i$ serão sufixais, uma vez que se tornam formas presas, fixando-se à base e caracterizando a formação como sendo um processo derivacional. O mesmo ocorre com a variante $-i m$, que se funde com a base. Em caxirim, por exemplo, o -im se funde com a base caxiri, tornando-se uma forma presa, e adquire propriedades sufixais sem o poder de mudar a classe gramatical da base.

b) Mesmo que haja uma RAE, pode não haver correspondência com uma RFP. Rocha (2008, p. 132-142) cita exemplos como florista, maquinista e artista, cuja RAE é $[[\mathrm{X}] \mathrm{s}]$-ista]s e RFP é [palestra]s'![palestra]s-ista] $=$ [paletrista]s, [zapata]s'![zapata]s-ista $]=$ [zapatista]s, formando novos vocábulos com base substantiva. As RAEs das palavras momentâneo, celeste, campestre, róseo e natalício, no entanto, não correspondem a RFPs, porque não há criação de novos vocábulos com os sufixos dessas palavras. Alguns desses sufixos também são encontrados em outras palavras em tempos pretéritos, tais como terrestre, marmóreo e adventício, por exemplo, mas não são mais utilizados atualmente para formar novas palavras. Pelo exposto e tendo em vista a produtividade dos adjetivos açu e mirim na formação de novas palavras, concluímos que, nesse caso, existe correspondência entre a Regra de Análise Estrutural (RAE) e Regra de Formação de Palavra (RFP).

c) A tarefa de fixação das RAEs difere em vários aspectos da fixação das RFPs. Existem formações nas quais não é mais possível realizar uma RAE, pois o falante não consegue perceber, em uma perspectiva sincrônica, o prefixo como em biscoito e objeto, nem o sufixo como em coxinha, caminhão, cabresto etc.

No geral, a forma açu seleciona, preferencialmente, bases substantivas relativas à flora e à fauna regional. O produto de açu é sempre uma base substantiva, com exceção da formação de adjetivos gentílicos, cujo produto será um adjetivo. Em algumas formações, a variante açu se funde com a base primitiva, como em сириaçu que, por sua vez, forma сириасиұеiro (CUNHA, 1999).

A produtividade da forma mirim é mais expressiva com bases substantivas, cujo produto será um substantivo, exceto as formações que envolvam bases toponímicas, que resultam em adjetivos gentílicos. A variante $-i$ se funde totalmente com a base, formando substantivos com outra significação e adquirindo totalmente propriedades sufixais, mas sem o poder de mudar a classe gramatical da base. Por exemplo, a junção de tucumã (substantivo)+-i é igual tucumãa (substantivo).

No geral, aģu e mirim concorrem com as formas do português, respectivamente "grande", forma analítica e adjetivo, e "-ão", forma sintética e sufixo, e "pequeno(a)", forma analítica e adjetivo, e "iinho(a)", "inho(a)", forma sintética e sufixo. Nos diferentes contextos, é possível o falante usar uma ou outra forma ou variante mesmo que haja restrições de uso para cada base. Por exemplo, com a base escoteiro + mirim formando 
escoteiro-mirim; embora seja possível a palavra escoteiro pequeno, a que usa a forma tupi é mais consagrada, embora não tenha sido encontrada nos dicionários pesquisados.

Nos dicionários Houaiss (HOUAISS et al., 2009), Aurélio (FERREIRA, 2009) e nos dicionários etimológicos, verificamos o registro das formações compostas de açu e mirim, sendo, portanto, consideradas entradas lexicalizadas, diferente de construções como barco grande, barco pequeno, homem grande, homem pequeno que não possuem registros como palavras compostas.

Açu e mirim são formas analíticas que participam, na maioria dos casos, da caracterização e quantificação de bases substantivas e atuam como elementos na formação de palavras compostas. As variantes de mirim, $-i m$ e $-i$, atuam como sufixos, sendo que, em algumas formações, fica difícil separá-las da base, uma vez que se aglutinam a ela.

As condições de produção das formas açu e mirim estão relacionadas ao ambiente amazônico e em outros espaços do território brasileiro com palavras formadas dentro do domínio semântico das leguminosas, como "carandâ" e "acari-açu", ou de acidentes geográficos como "paraná-mirim", "igarapé-açu". E as condições de produtividade estão relacionadas à base que essas formações selecionam.

Nos compostos com af̧ $u$ e $m$ irim, em princípio, a base, na maioria dos casos, é substantiva, contribuindo para a formação de novos vocábulos com outra carga semântica, pois é um novo referente que está sendo denominado. A maioria das bases selecionadas é de origem tupi.

\section{Conclusões}

Os adjetivos açu e mirim caracterizam formações pelo processo de composição e fazem parte do léxico relativo à fauna, à flora regional, a acidentes geográficos e a topônimos (DIETRICH; NOLL, 2010), mas, eventualmente, podem representar sufixos e, como tal, fazer parte de processos derivacionais. Além das formas compostas com o adjetivo açu, foram encontradas outras variantes como guaçu, uçu e, em alguns livros, com a grafia em -ss-. Já para a variável (mirim), foram identificadas as variantes mirim, mirił, im e $i$, sendo que estas duas últimas formam palavras pelo processo derivacional, uma vez que adquirem propriedades sufixais.

O significado de aģu é equivalente ao adjetivo "grande" e o de mirim, ao adjetivo "pequeno". São, portanto, antônimas. Nem todas as formações com mirim selecionam bases substantivas. Por exemplo, as palavras mirim-guaçu, mirim-pintada não são constituídas de bases substantivas.

Diferentemente da forma açu, mirim forma novos vocábulos também com anteposição à base primitiva. Além disso, constatamos que formações envolvendo açu e suas variantes, bem como mirim e suas variantes, possuem entrada nos dicionários pesquisados. 
Concluímos que, se existe uma gama extensa de palavras formadas com açu e suas variantes, e também com mirim e suas variantes, ou seja, esses adjetivos de origem tupi, incorporados ao português brasileiro, são bastante produtivos na formação de palavras compostas e, por vezes, na formação de palavras por derivação com o uso das variantes $i m$ e $i$.

Embora seja possível a construção de novas palavras com açu e mirim, a existência no português das formas "grande", "-ão", "pequeno(a)", "-zinho(a)", "-inho(a)" tende a bloquear novas formações com esses adjetivos de origem tupi.

Como se trata de formação de novas palavras pelo processo de composição envolvendo açu e mirim, em português, a partir de bases pré-existentes na língua, a maioria de origem tupi, foi possível verificar a existência de RAEs e a aplicação de RFPs. O mesmo é válido para o processo de formação de palavra por derivação, envolvendo as variantes de mirim: im e $i$.

As formações por composição são estruturas lexicalizadas e a maioria delas possui entradas nos dicionários pesquisados. Embora as formações com açu e mirim sejam nomes populares, ou seja, sem a denominação científica, o léxico relativo aos domínios semânticos da flora e da fauna é pouco usado pela maioria das pessoas.

Existem formações que não foram catalogadas, pois não conseguimos indicar a fonte. São elas: abati-timbaí, acurí, guai, guraí, ibiracui, juí, juiguaraigaraí, pacuí, paraí, potiguaçu, sui, taciai, urataí, vapuí, paumirim e itantim. Trata-se, portanto, de formas lexicais que exigem aprofundamento de pesquisa para poderem ser mais bem analisadas.

\section{Referências}

AGUIAR, M. O.; FREITAS, E. N. M. Plantas da Ilha Duraka. Estudo etnobotânico. São Gabriel da Cachoeira: Valer, 2005.

ALENCAR, J. M. de. Ubirajara: lenda tupi. 2012. Edição do Kindle.

ALENCAR, J. M. de. Iracema. Câmara, 2018. Edição do Kindle. (Série Prazer de Ler).

ALVES, I. M. Formações prefixais no português falado. In: CASTILHO, A. T. de. (Org.). Gramática do português falado. v. 2. 3. ed. Campinas: Ed. da UNICAMP, 2002. p. 383-398.

ANDRADE, M. de. Macunaíma. São Paulo: Novo Século, 2017.

ARONOFF, Mark. Word formation in Generative Grammar. Cambridge, MA: MIT Press, 1976. 
AZEVEDO, O. da S. Aspectos dialetais do português da região norte do Brasil: um estudo sobre as pretônicas e sobre o léxico no Baixo Amazonas (PA) e no Médio Solimões (AM). 2013. Tese (Doutorado em Linguística) - Universidade Federal de Santa Catarina, Florianópolis, 2013.

AZEVEDO, O. da S.; MARGOTTTI, F. W. O sufixo -rana no português falado pelo caboclo amazonense. Alfa, São Paulo, v. 56, n. 2, p. 611-621, 2012. Disponível em: https://bit.ly/2A7c2U3-rana. Acesso em: 12 maio 2019.

BARBOSA, E. M. et al. Frutos de palmeiras da Amazônia. Manaus: INPA, 2001.

BASÍLIO, M. et al. Derivação, composição e flexão no português falado. In: CASTILHO, A. T. de. (Org.). Gramática do português falado. Campinas: Ed. da Unicamp: FAPESP, 1980. v. 3. p. 363-429.

BASÍLIO, M. Formação e classes de palavras no português do Brasil. 2. ed. São Paulo: Contexto, 2009.

CARREIRA, L. M. de M. et al. Nomes populares das leguminosas do Brasil. Manaus: EDUA, 2004.

CHOMSKY, N. Novos horizontes no estudo da linguagem. DELTA, São Paulo, v. 13, n. esp., p. 51-74, ago. 1997.

CUNHA, A. G. da. Dicionário histórico das palavras portuguesas de origem tupi. Brasília: UnB, 1999.

DIETRICH, W.; NOLL, V. O papel do tupi na formação do português brasileiro. In: DIETRICH, W.; NOLL, V. (Org.). O português e o tupi no Brasil. São Paulo: Contexto, 2010. p. 81-103.

FERREIRA, A. B. H. Novo dicionário da língua portuguesa. Rio de Janeiro: Nova Fronteira, 2009.

GLOSSÁRIO Tupi-Guarani Ilustrado. Lebooks, 2018. Edição do Kindle. (Coleção História Viva).

HOUAISS, A. et al. Dicionário Honaiss da lingua portuguesa. Rio de Janeiro: Objetiva, 2009.

MELLO, O. Dicionário tupi-português/português tupi. Manaus: EDUA, 2003.

MENDONÇA, M. C. A Amazônia na era pombalina. 2. ed. t. 2 e 3. Brasília: Senado Federal, 2005. 
RIO-TORTO, G. M. Morfologia derivacional. Porto: Porto, 1998.

ROCHA, L. C. de A. Estruturas morfológicas do português. 2. ed. São Paulo: MWF Martins Fontes, 2008.

SPENCER, A. Morphological theory. Oxford: Blackwell, 1991.

WITTMANN, F. et al. Manual de árvores da Amazônia: taxonomia, ecologia e uso.

Manaus: INPA, 2010. 